\title{
QUALIDADE MICROBIOLÓGICA DE ÁGUAS TRATADAS E NÃO TRATADAS DE DIVERSOS LOCAIS DO ESTADO DE SANTA CATARINA
}

\author{
KÁTIA LOTIN* \\ HONÓRIO DOMINGOS BENEDET**
}

\begin{abstract}
Verificou-se a qualidade de águas tratadas e não tratadas com relação as suas caracterísicas organolépticas, enfocando-se principalmente a presença de microrganismos do tipo coliforme. Os resultados obtidos mostraram elevado índice de contaminação de amostras de águas tratadas e não tratadas, o que contraria a legislação vingente.
\end{abstract}

\section{INTRODUÇÃO}

No século passado o consumo de água pelo homem limitava-se a usos essenciais, ou seja, como bebida e no preparo de alimentos. Com o passar do tempo, os hábitos de higiêne, a indústria e o aumento da população exigiram maior quantidade de água para os mais diversos fins. Água pura praticamente não existe, pois estando em contato com a natureza torna-se sujeita à contaminação natural e também à poluição causada pelo homem (4).

A água consumida pelos seres vivos, especialmente pelo homem, deve estar livre de substâncias nocivas e tóxicas. Entretanto, pela própria natureza muitas substâncias nocivas à saúde humana, que se encontram no solo em forma de compostos solúveis, podem ser transportadas para os mananciais e contaminar a água potável (4).

As enfermidades causadas ao ser humano pela água têm alcançado índices muito elevados, tornando essencial o controle da qualidade da água de maneira contínua, visando segurança no abastecimento das populações (4). Além da contaminação natural, a água potável

* Farmacêutica-bioquímica Tecnóloga de Alimentos da Universidade Federal de Santa Catarina.

** Professor Titular do Departamento de Ciência e Tecnologia de Alimentos da Universidade Federal de Santa Catarina. 
pode torna-se depositária de substâncias tóxicas para o homem, animais e plantas através de resíduos oriundos da agricultura intensiva, do desenvolvimento industrial descontrolado, de depósitos sanitários mal concebidos, por material e tubulação inadequados ou mesmo através de incorreta dosagem de substâncias químicas durante o tratamento (4). O controle sanitário de águas prevê testes físicos, químicos, microscópicos e bacteriológicos (3).

Com o presente trabalho realizou-se análises de águas tratadas (abastecimento público) e não tratadas (poços, riachos, nascentes, etc.), tanto microbiológicas quanto fisico-químicas, verificando-se a potabilidade da água, o grau de poluição, as fontes poluidoras e o controle das etapas em estações de tratamento.

\section{MATERIAL E MÉTODOS}

Utilizou-se as técnicas de coleta de amostras recomendadas pelas Normas Analíticas do Instituto Adolfo Lutz e de acordo com o Decreto Lei $n^{\circ} 986$ de 21/10/69, que institue normas básicas sobre alimentos da Comissão Nacional de Normas e Padrões para Alimentos (2).

As amostras de água tratadas e não tratadas foram coletadas em frascos esterilizados, com tampa esmerilhada. Para a água tratada coletou-se duas amostras, uma destinada ao exame fisico-químico (dosagem de cloro) e outra ao exame bacteriológico. A estas adicionou-se antes da esterilização $0,1 \mathrm{~mL}$ de tiossulfato de sódio a $10 \%$, com a finalidade de inibir a ação bactericida do cloro. A quantidade de amostra coletada não foi inferior a $100 \mathrm{~mL}$ e seu transporte ao laboratório feito sob refrigeração, num tempo máximo de 24 horas (2).

A dosagem de cloro foi realizada de acordo com as Normas Analíticas do Instituto Adolfo Lutz (2). Para as análises microbiológicas foi utilizada a técnica dos tubos múltiplos (NMP) recomendada pelo Standard Methods for the Examination of Water and Waste Water (1).

\section{RESULTADOS E DISCUSSÃO}

Nas Tabelas 1 e 2 observa-se que, das 36 amostras analisadas, 19 são de águas não tratadas. Destas, apenas 7 estão de acordo com os padrões micribiológicos de potabilidade estabelecidos pela Portaria 56 Bsb do Ministério da Saúde, por não apresentarem contaminação por germes do grupo coliforme total. A presença destes microrganismos torna estas águas condenadas, pois são destinadas para consumo humano. 
TABELA 1 - RESULTADO DA ANÁLISE MICROBIOLÓGICA DE ÁGUAS NÃO TRATADAS

\begin{tabular}{|c|c|c|c|c|c|c|}
\hline \multicolumn{5}{|c|}{ CARACTERÍSTICAS ORGANOLÉPTICAS } & \multicolumn{2}{|c|}{ EXAME MICROBIOLÓGICO } \\
\hline AMOSTRA & $\begin{array}{l}\text { LOCAL DE } \\
\text { ORIGEM }\end{array}$ & SABOR & ASPECTO & ODOR & $\begin{array}{l}\text { COLIFORMES } \\
\text { TOTAIS }\end{array}$ & $\begin{array}{l}\text { COLIFORMES } \\
\text { FECAIS }\end{array}$ \\
\hline A & poço (Santo Amaro da Imperatriz) & caract. & límpido & caract. & presença * & presença * \\
\hline $\mathrm{B}$ & poço (Aeroporto-Fpolis) & caract. & ligeiramente turva & caract. & ausência & ausência \\
\hline $\mathrm{C}$ & poço (Aeroporto-Fpolis) & caract. & ligeiramente turva & caract. & ausência & ausência \\
\hline $\mathrm{D}$ & poço (São José) & caract. & límpida & caract. & presença * & ausência \\
\hline $\mathrm{E}$ & nascente (Rio do Oeste) & caract. & límpida c/sujidade & caract. & presença * & presença * \\
\hline $\mathrm{F}$ & nascente (Rio do Oeste) & caract. & límpida c/sujidade & caract. & presença * & presença * \\
\hline $\mathrm{G}$ & nascente (Rio do Oeste) & caract. & límpida & caract. & presença * & presença * \\
\hline $\mathrm{H}$ & nascente (Rio do Oeste) & caract. & límpida c/depósito & caract. & presença * & presença * \\
\hline $\mathrm{I}$ & riacho Canasvieiras-Fpolis) & caract. & amarelada & caract. & presença * & ausência \\
\hline $\mathrm{J}$ & poço (Lagoa da Conceição-Fpolis) & caract. & amarelada & caract. & ausência & ausência \\
\hline $\mathrm{K}$ & nascente (Fpolis) & caract. & levemente amarelada & caract. & presença * & presença * \\
\hline $\mathrm{L}$ & poço (Lagoa da Conceição-Fpolis) & caract. & límpida & caract. & ausência & ausência \\
\hline M & poço (Fpolis) & caract. & límpida & caract. & ausência & ausência \\
\hline $\mathrm{N}$ & nascente (São José) & caract. & levemente amarelada & caract. & presença * & presênca * \\
\hline $\mathrm{O}$ & poço (Campeche-Fpolis) & caract. & límpida & caract. & ausência & ausência \\
\hline $\mathrm{P}$ & poço (Campeche-Fpolis) & caract. & límpida & caract. & ausência & ausência \\
\hline $\mathrm{Q}$ & poço (Agronômica-Fpolis) & caract. & límpida & caract. & presença * & presença * \\
\hline $\mathrm{R}$ & poço (Serraria-Fpolis) & caract. & límpida & caract. & presença * & ausencia \\
\hline $\mathrm{S}$ & poço (Serraria-Fpolis) & caract. & límpida & caract. & presença * & presença * \\
\hline
\end{tabular}

* = Amostra em desacordo com os valores estabelecidos pela legislação.

caract. $=$ característico. 
TABELA 2 - RESULTADO DA ANÁLISE MICROBIOLÓGICA DE ÁGUAS TRATADAS

\begin{tabular}{|c|c|c|c|c|c|c|}
\hline \multicolumn{5}{|c|}{ CARACTERÍSTICAS ORGANOLÉPTICAS } & \multicolumn{2}{|c|}{ EXAME MICROBIOLÓGICO } \\
\hline AMOSTRA & LOCAL DE ORIGEM & SABOR & ASPECTO & ODOR & $\begin{array}{l}\text { CONCENTRAÇÃO DE } \\
\text { CLORO (PPM) }\end{array}$ & $\begin{array}{l}\text { COLIFORMES } \\
\text { TOTAIS }\end{array}$ \\
\hline $\mathrm{A}$ & Casan (LBA-Fpolis) & caract. & límpida & caract. & 0,0 & ausência \\
\hline $\mathrm{B}$ & Casan (LBA-Fpolis) & caract. & límpida & caract. & 0,0 & ausência \\
\hline $\mathrm{C}$ & Casan (LBA-Fpolis) & caract. & límpida & caract. & 0,5 & ausência \\
\hline $\mathrm{D}$ & Casan (LBA-polis) & caract. & límpida & caract. & 0,7 & ausência \\
\hline $\mathrm{E}$ & Casan (LBA-Fpolis) & caract. & límpida & caract. & 0,5 & ausência \\
\hline $\mathrm{F}$ & Casan (LBA-Fpolis) & caract. & límpida & caract. & 0,7 & ausência \\
\hline $\mathrm{G}$ & Casan (LBA-Fpolis) & caract. & límpida & caract. & 0,1 & ausência \\
\hline $\mathrm{H}$ & Casan (LBA-Fpolis) & caract.. & amarelada & caract. & 0,0 & ausência \\
\hline $\mathrm{I}$ & Casan (Fpolis) & caract. & amarelada & caract. & 0,2 & presença * \\
\hline $\mathrm{J}$ & Casan (Fpolis) & caract. & límpida & caract. & 0,0 & presença * \\
\hline $\mathrm{K}$ & Casan (Fpolis) & caract. & límpida & caract. & 0,0 & presença * \\
\hline $\mathrm{L}$ & Casan (Fpolis) & caract. & límpida & caract. & 0,3 & presença * \\
\hline M & Casan (LAFESC-Fpolis) & caract. & límpida & caract. & 0,0 & ausência \\
\hline $\mathrm{N}$ & Casan (LAFESC-Fpolis) & caract. & límpida & caract. & 0,0 & ausência \\
\hline $\mathrm{O}$ & Casan (LAFESC-Fpolis) & caract. & $\begin{array}{l}\text { Levemente } \\
\text { amarelada }\end{array}$ & caract. & 0,0 & ausência \\
\hline $\mathrm{P}$ & Casan (LAFESC-Fpolis) & caract. & límpida & caract. & 0,0 & ausência \\
\hline $\mathrm{Q}$ & Casan (LAFESC-Fpolis) & caract. & límpida & caract. & 0,4 & ausência \\
\hline
\end{tabular}

caract - característico; Casan - Companhia Catarinense de Água e Saneamento; LAFESC - Laboratório Farmacêutico do Estado de Santa Catarina; * Amostra em desacordo com os valores estabelecidos pela legislação; Conc. de cloro (ppm) - concentração de cloro ativo em partes por milhão. 
Para águas "in natura", ou seja, aquelas que não receberam tratamento físico e químico, estende-se a pesquisa até os germes do grupo coliforme fecal (indicador de poluição por fezes de animais de sangue quente), supondo-se que poderá apresentar também outras bactérias extremamente patogênicas, bem como vírus, provenientes de contato com material fecal.

Dentre as águas tratadas, 4 amostras estavam em desacordo com os padrões microbiológicos de potabilidade estabelecidos pela Portaria 56 Bsb, do Ministério da Saúde, por apresentarem contaminação por germes do grupo coliforme total. A simples presença de coliformes totais as condenam, uma vez que são destinadas ao consumo humano.

O alto índice de amostras de águas tratadas em desacordo com a legislação, provavelmente se deve a falta de limpeza das caixas d'água ou reservatórios periodicamente como seria aconselhável (6 em 6 meses). A proximidade com fossas sépticas ou esgotos também pode contaminar lençóis freáticos (águas provenientes de poços simples e de ponteiras).

É aconselhável que se repita as amostras positivas no caso de águas tratadas de torneiras de residências ou outros locais, colhendo-se simultaneamente uma amostra direto da rede, para detectar a real causa da contaminação, ou seja, se o problema está no encanamento, no reservatório da residência ou se veio da rede de abastecimento público.

Para se condenar águas do sistema de abastecimento público é necessário que se colha várias amostras e que as mesmas acusem presença de coliformes totais da seguinte maneira:

- de todas as porções padrão de $10 \mathrm{~mL}$ examinadas por ano, semestre ou mês, não mais que 10\% (dez por cento) poderão revelar a presença de germes do grupo coliforme, quando a técnica de exame bacteriológico for a dos tubos múltiplos.

- eventualmente três ou mais, de cinco porções padrão, componentes de uma amostra padrão poderão conter germes do grupo coliforme, desde que isto não ocorra em amostras consecutivas ou em mais de $5 \%$ (cinco por cento) do total de amostras examinadas.

- eventualmente uma amostra padrão pode apresentar até quatro ou mais coliformes por $100 \mathrm{~mL}$, desde que isto não ocorra em amostras consecutivas ou em mais de $5 \%$ do total das amostras analisadas.

- no caso de amostras colhidas aleatoriamente, isto é, sem pertencerem a uma amostragem, pode-se condenar apenas a amostra que estiver em desacordo com os padrões microbiológicos de qualidade, conforme a Portaria 56 Bsb. 
Também são realizadas análises para detectar teores elevados de cloro (total) e fluor (íons fluoreto) nas águas de abastecimento público, bem como exames de balneabilidade para águas de contato primário.

\section{CONCLUSÃo}

O elevado índice de amostras de águas tratadas em desacordo com a legislação provavelmente ocorreu por falta de limpeza e desinfecção periódicas nas caixas d'água e reservatórios. No caso das águas não tratadas (águas de poço, nascentes e riachos), a contaminação por coliformes pode ter ocorrido pela proximidade com fossas sépticas e esgotos sanitários inadequados.

\section{ABSTRACT}

From a survey carried out on the quality of untreated and treated water, a high degree of Escherichia coli contamination was observed for both groups of samples, higher than the official limit levels.

\section{REFERÊNCIAS BILBLIOGRÁFICAS}

1 AMERICAM PUBLIC HEALTH ASSOCIATION. Standard methods for the examination of water and wastewater. 13. ed. New York, 1971.

2 INSTITUTO ADOLFO LUTZ. Métodos químicos e físicos para análise de alimentos. 2. ed. São Paulo, 1985.

3 OLIVEIRA de, F., AKISUE, G. \& AKISUE, M. K. Curso prático de microscopia alimentar. São Paulo, 1984.

4 UNIVERSIDADE FEDERAL DE SANTA CATARINA. Apostilas e anotações. Florianópolis, 1978. 